\title{
OS SENTIDOS DA ARTE
}

Miguel Almir L. de Araújo ${ }^{1}$

Resumo: O texto emerge de experiências e meditações desenvolvidas de modo teórico e empírico durante as minhas trajetórias profissionais. Trata da Arte como modo próprio de conhecimento que se constitui desde as esferas da intuição, da imaginação criante, da consciência compreensiva, da corporeidade, das afecções (emoções e sentimentos), do espírito crítico-criador. Arte como expressão de formas simbólicas que mobilizam as dimensões vastas e fundas da sensibilidade humana, da poeticidade do existir. Como expressão da poiesis, dos processos poéticos de criação, que, dessa forma, incidem na transgressividade e na transfiguração do real mediante seus símbolos mitopoéticos. Símbolos que plasmam formas inaugurais instaladoras de significados e de sentidos que dão intensidade, cromaticidade e encantamento ao existir. Arte como experiência intensiva de fruição da sensibilidade e que potencializa entrelaces e compartilhamentos humanos, momentos profícuos de celebração da vida.

Palavras-Chave: Arte, Poeticidade, Re-encantamento.

Abstract: The text emerges from experiences and meditations developed in a theoretical and empirical manner during my professional trajectories. It deals with Art as a proper mode of knowledge which is built from the intuition spheres of the creating imagination, from the comprehensible conscience, from corporeity, from affections (emotions and feelings), from the criticalcreator spirit. Art as an expression of symbolic forms that mobilize broad and deep dimensions of human sensitiveness, of the poetry of being. As an expression of poeisis, of the poetic processes of creation, which fall upon the transgressive quality and in the transfiguration of reality by means of its mythic-poetical symbols. Symbols which mold inaugural forms that bring about meanings and sense that give intensity, color and enchantment to existence. Art as an intensive experience of fruition of sensibility, which strengthens human interlacements and sharing - advantageous moments to celebrate life.

Keywords: Arte, Poetricity, Re-enchantment.

1 Professor do Departamento de Educação da Universidade Estadual de Feira de Santana (UEFS); Doutor em Educação; Coordenador do Núcleo de Investigações Transdisciplinares (NIT). Endereço eletrônico: malmir2@gmail.com. 
A vida só é possível pelas miragens da arte

(Nietzsche).

\begin{abstract}
El arte es una forma cósmica que a través de sus pulsaciones y ritmos, nos conduce a la unidad, reflejando así la estructura profunda de la realidad última
\end{abstract}

(Carlos D. Fregtman).

A revelação dessa inesgotabilidade dos aspectos das coisas é um dos grandes privilégios e um dos mais profundos encantos da arte

(Ernst Cassirer).

A Arte, como uma das formas singulares de expressão da condição humana, como um modo próprio de conhecimento, em suas expressões simbólicas que incidem na transfiguração do real, se consubstancia mediante a força intensiva e a fruição da imaginação criante adubada pela fantasia, pelo onírico, pelo imaginário mitopoético; dos sentimentos e desejos, paixões e crenças mais viscerais; dos feixes da intuição, do senso agudo e sutil que emerge desde dentro; do elã da espiritualidade, do anímico ao penetrar nos desvãos da alma, do sopro que anima; da consciência compreensiva em que uma razão alargada e sensível conduz a compreensões vastas; da corporeidade mediante as in-tensidades de sua pregnância existencial.

Como forma própria de conhecimento, a Arte penetra nos confins oblíquos da condição humana potencializando, através da plasticidade das formas expressivas dos seus símbolos, processos de criação e de recriação de Sentidos imbuídos de poeticidade. Alarga nossos sensos perceptivos os cinco sentidos, bem como, outros que daí se descortinam - ao mobilizar nossa sensibilidade, imaginação e espírito criantes. Mediante os tons de sua singularidade, a Arte apresenta novas formas de compreensão e de vivenciação do existir, do mundo.

Desse modo, a Arte implica no cuidado e na fruição da sensibilidade humana, em suas dimensões expansivas e fundas, mobiliza o espírito inventivo e altaneiro, o senso de espirituosidade; se configura como forma de expressão dos Sentidos humanos que se plasmam de modo teóricovivencial, pregnante e anímico, mobilizando os repertórios estruturantes da inteireza in-tensiva da condição humana. A expressão in-tensiva/in-tensivo supõe conceber que a condição humana é constituída, ontologicamente,

122 Número temático: Desenho e Educação: Cultura Visual e Cidade. A Cor das Letras - UEFS, n. 
por estados de tensividade constante no dinamismo de seus (in)fluxos moventes.

A fruição da Arte implica no cultivo acurado e sensível dos chamados cinco sentidos bio-físico-químicos. Na proporção em que estes são burilados com afinco, penetramos nas instâncias do senso intuitivo, nas estruturas vastas da sensibilidade, nos territórios da delicadeza, da fineza, da espirituosidade e da poeticidade do existir. Desde os cinco sentidos mais elementares podemos atingir os Sentidos primordiais do existir.

A Arte emerge de nossa relação de espanto e de assombro diante dos fluxos tensoriais e da porosidade das contingências cotidianas e se materializa com os fluxos da imaginação criante através dos símbolos polifônicos que traduzem luzes e sombras, a franja da penumbra, do crepuscular, do admirável do existir humano, se enredando por seus meandros incomensuráveis e indeterminados. Como forma própria de conhecimento que se plasma através da polifonia de suas formas simbólicas, a Arte penetra e garimpa as sendas descomunais dos enigmas que constituem os desvãos do ser-sendo, dos paradoxos e dos imponderáveis que perfazem o existir. Jung (1991, p. 89) realça que a Arte "Provinda do espírito e do coração, fala ao espírito e ao coração da humanidade". Evoca e nos mergulha na imensidão e nas reentrâncias do pregnante e do anímico, do co-movente e do alumbrante, da tragicomicidade da humanidade, do universo.

A palavra Arte se origina do latim ars, artis correspondendo ao tekné grego e se traduz na utilização de meios para obtenção de fins. No decurso da história da cultura humana, esta expressão vai tomando traços específicos significando, assim, um fazer mais primoroso, imbuído de imaginação, de poeticidade e do espírito de fineza. Um fazer da poiesis. Um criar poético. Um modo de criação e de plasmação de formas expressivas imbuídas de sensibilidade e de poeticidade, de paixão e de razão. O fazer artístico é uma criação singular originária que estampa os tons do admirável e a relação encantatória dos seres humanos consigo mesmos e com o cosmos. Mobiliza in-tensivamente o corpo e a alma mediante processos de criação e de metamorfoses que dão plasticidade e alumbramento ao existir humano.

Ao rebentar das dimensões mais sinuosas e imensuráveis do existir humano a Arte se constitui através das linguagens peculiares de seus símbolos com suas imagens polissêmicas: a Dança, a Música, o Teatro, a Literatura, a Poesia, as Artes plásticas... Esses símbolos, com seus tons mestiços, revelam as texturas inefáveis dos sentires, das paixões, dos sonhos, dos encurvamentos do humano. Traduzem, de modo pregnante e anímico, as 
ambiguidades e paradoxos do existir e do co-existir; estampam as silhuetas desse existir demasiadamente humano, nos rasgos de suas in-tensidades, em seu estado nascente e ad-mirante, vivente e originário.

A Arte penetra na fundeza dos recônditos incontornáveis da vida mobilizando nosso daimon volvente, suas camadas sutis e enigmáticas. Impulsiona o pathos, a paixão que espanta. Pro-voca perplexidade e compele às aventuras extraordinárias. Com seu espírito de transgressividade, as linguagens de Arte subvertem os clichês cristalizados que recalcam e interditam as expressões originárias e dionisíacas que são afirmadoras da vida no desbordar de sua exuberância. Cassirer (1994, p. 244) proclama: "Mas a arte transforma todas essas dores e ultrajes, essas crueldades e atrocidades, em um meio de autolibertação, conferindo-nos assim uma liberdade interior que não pode ser atingida de nenhum outro meio". Potencializa, alquimicamente, a transformação do lodo em lótus mediante as metamorfoses re-criadoras do existir. Conduz às buscas do autoconhecimento, das emancipações que nos trans-formam. A Arte instaura rebeliões que fazem jorrar os sonhos e utopias que animam o viver.

A Arte é extraordinária enquanto forma de expressão essencialmente criadora, instituinte e transfiguradora. Os elementos e fenômenos mais banais são apropriados pelo artista e transfigurados nas formas da Arte que despertam sensações e Sentidos novos, inaugurais. Ao transfigurar o real, a Arte o re-cria, re-inventa, trans-forma, institui o novo. Assim, nos abre para o desbordar dos sentimentos da "eterna novidade do mundo" (PESSOA, 1980, p. 35); nos renova, nos torna redivivos.

No bojo de uma sociedade estruturada, de modo predominante, sob os auspícios de uma cultura mercantilista, portanto, utilitária e consumista, a vivência e a fruição da Arte fica secundarizada e comprimida na proporção em que esta, nesses contextos de pragmatismos funcionais e imediatistas, se torna inútil. Ou então é reduzida a mero espetáculo anestésico, a mero artefato mercadológico. A Arte penetra nas esferas do ter, do quantitatvo, da forma material, mas não se reduz a essas instâncias. Atravessa o campo dos significados, do imediato, do instrumental, e desborda-se nas searas do ser, dos Sentidos, da terceira margem, do anímico. Ela nos conduz às esferas da sutileza, da fineza, do qualitativo, aos feixes dos Sentidos humanos primordiais.

Como fenômeno estésico, a plasticidade da Arte mobiliza a nervura do sensível desencadeando sensações emancipadoras; impulsiona os fluxos da sensibilidade e da imaginação criantes dos indivíduos. Quando reduzida 124 Número temático: Desenho e Educação: Cultura Visual e Cidade. A Cor das Letras - UEFS, $n$. 
a propósitos anestésicos, na mutilação e na desqualificação de seu estado poético, de seu elã criante, o uso da Arte incide no emplastamento, na desfiguração e na compressão da sensibilidade e da imaginação criantes.

O cientificismo é outra vertente ainda predominante em nossa sociedade que, em grande medida, também desemboca na subestimação e na obliteração da Arte. Na proporção em que a Ciência é considerada como campo único de conhecimento e de verdade, onde o que não for explicado cientificamente é desqualificado e deslegitimado, a Arte é concebida como algo irrelevante e inconsistente. Parece que no mundo contemporâneo estamos, processualmente, rompendo com a hegemonia dos reducionismos desses paradigmas exclusivistas que elegem a Ciência como único modo de conhecimento pertinente. Parece que começamos a compreender que a condição humana se constitui desde suas múltiplas dimensões que incluem, de modo complementar e coexistente, a Ciência, a Filosofia, a Arte e as Tradições espirituais/espiritualidade.

Despontando dos fulcros magmáticos do existir humano, a Arte se consubstancia como experiência vívida em que cada indivíduo, nos processos de criação e de fruição, vivencia com intensidade a expressão dos enigmas policrômicos da beleza através da polissemia de seus Sentidos. É um conhecimento marcado pelo sorver vivencial que agrega, em suas formas expressivas, a imaterialidade da ideia/pensamento e a materialidade da nervura do vivido/vivente. A vivência artística implica em mobilizar nossas sensações, em sermos atravessados de corpo inteiro pelas texturas e pregnâncias das experiências que nos en-volvem e mobilizam; que nos provocam sustos e arrepios; que traduzem a fruição do degustar com todos os sentidos interligados.

A Arte, através de sua multiplicidade de formas expressivas e de suas intensidades, impulsiona a lapidação dos sentimentos mais nobres. Conduz a afinação do instrumento que conjuga o dentro e o fora. As miragens da Arte comovem. Movem o coração que pulsa flamejante; estampam os tons mestiços que dão cromaticidade à condição humana. Toca as cordas da alma entoando a melodia do esprit de finesse, da fineza do ser-sendo. Cassirer (1994, p. 244) realça: "A arte nos apresenta os movimentos da alma humana em toda a sua profundidade e variedade". Co-move o corpo inteiro na vertigem indecifrável das sensações de dor e de prazer, da exultância de sentimentos indizíveis fazendo desbordar o elã vital. Nos inquieta e perturba, mas também nos põe em estado de graça podendo nos tornar, assim, mais graciosos. 
A produção artística supõe articular, entrelaçadamente, forma e conteúdo. A forma revela a estrutura e a configuração material e visível da obra de Arte. Para plasmar a forma artística torna-se necessário a utilização da técnica como conjunto de procedimentos que permitem a operacionalização da obra. É o seu modus operandi. A forma que é plasmada através da técnica se configura como estrutura material e tangível da linguagem artística. O conteúdo revela os significados e Sentidos que se descortinam na obra desde sua disposição formal. Revela o intangível mediante a intensidade das ideias, valores e sentimentos que emergem visivelmente na plasticidade das formas. Portanto, forma e conteúdo são instâncias interdependentes e complementares na composição dos símbolos artísticos. A forma artística torna visível e tangível a intangibilidade dos Sentidos, do estado poético.

O estado poético, para Morin (2002, p. 136), "é um estado de emoção, de afetividade, realmente um estado de espírito [...] proporciona satisfações carnais e espirituais". O estado poético se constitui como estado de dis-posição, de abertura e de despojamento do complexo interdependente e entrelaçado de nosso corpo e de nossa alma para a fruição das intensidades pregnantes e anímicas, da policromia e da plasticidade dos fenômenos do existir humano. "É um estado de ser em que o existir humano é comovido pelo pathos do admirável, con-vocado pelo espanto que arrepia o corpo e lampeja o espírito. [...] descortina a postura entusiasmante e nos enreda nas franjas do extraordinário" (ARAÚJO, 2008, p. 125 e 128).

As formas simbólicas das miragens da Arte penetram com intensidade nos meandros imponderáveis das curvaturas do existir, na multiplicidade de nossos modos de ser e de estar sendo no mundo marcados por conflitividades, ondulações e desmesuras. Jung (1991, p. 65) assevera que "O símbolo é sempre um desafio à nossa reflexão e compreensão. Daí o fato de a obra simbólica nos sensibilizar mais, mexer mais com o nosso íntimo". Os símbolos da Arte atravessam nossas intimidades, nossas texturas sensíveis, os tremores da tragicidade do humano; se nutrem de sua tragicomicidade. As intensidades da Arte nos precipitam no âmago dos desafios e dos rasgos que constituem a carne do humano, as dores do mundo; garimpam suas contradições e nos inspiram para ousarmos nas itinerrâncias das travessias que alteram, transmutam e renovam. A poeticidade dos símbolos expressivos da Arte apresenta feixes de vivacidade que nos comovem, vicejam e alumbram. 
$\mathrm{Na}$ encruzilhada entre a franja do mistério que povoa a noite - no reinado da lua - , e dos flancos que cintilam o dia - no reinado do sol - , rebentam as intensidades da Arte. Ela sopra os segredos dos desvãos incontornáveis do existir escorrendo nas dobras recurvadas de nosso ser-sendo. Configura um elo formoso que interliga o profano e o sagrado, o céu e a terra, o espírito e a matéria. Em sua constituição pregnante e anímica, as expressões da Arte implicam na coexistência fecunda e in-tensiva entre a existencialidade do corpo e da alma. A Arte faz desbordar a fruição do mais sutil e penetrante da sensibilidade humana, dos feixes da poeticidade do existir, proporcionando a emergência de processos que vivificam e incidem em encantação.

As expressões da Arte, através da policromia, da polifonia e da plasticidade de seus símbolos, imbuídos de sensibilidade e de espirituosidade, e com suas potencialidades ligantes, interligantes e religantes, entrecruzam dentro e fora, sentires e pensares, masculino e feminino; mobilizam o imaginário mitopoético de cada ser-sendo e conduzem à fruição do estado poético que espanta e arrepia.

Os símbolos da Arte são constituídos de uma Razão-Sentido como expressão de um pensar, de um pensamento aberto e meditativo que, com espirituosidade, se traduz numa razão compreensiva, encarnada. Uma Razão que, configurada com seus horizontes vastos, pondera e medita dialogicamente, compreendendo suas possibilidades e limites - uma Razão sensível (ARAÚJO, 2008).

Com o jogo sincopado da plasticidade estésica de suas formas, as proezas da Arte nos incursionam no dinamismo do sensível, do pulsar das afeç̧ões (emoções e sentimentos), do lampejar da poeticidade do existir. Atravessa suas penumbras; flecha o indizível. A Arte nos co-move de corpo e alma ao nos proporcionar a fruição pregnante e anímica do ad-mirável, dessa poeticidade crepuscular dos fenômenos do existir. Ao penetrar em nossas dimensões mais fundas e sutis, nos projeta nas reentrâncias de nosso imaginário mitopoético e nos conduz ao "sentimento do mundo" (ANDRADE, 2000, p. 133), aos enigmas do humano; desborda a gratuidade e a inefabilidade das inutilezas que ressoam nos cafundós da alma e do coração.

As expressões simbólicas da Arte emergem dos influxos de nossas inquietudes e duvidações, da nervura de nossas angústias e contentezas, de assombros e perplexidades; atravessam os rasgos dos fluxos tensoriais do existir contingente. Com o seu impulso criador e senso fino para com as 
coisas demaismente humanas, a potência vigorosa de seu espírito de transgressividade instala transgressões diante da normalidade do ordinário, dos modelos instituídos que aprisionam as paixões e utopias humanas. Ao nos precipitar no extraordinário, a Arte provoca reconfigurações e mutações de pensares, sentires e aconteceres; transfigura o real plasmando novas formas e Sentidos eivados da policromia e das intensidades dos ermos do humano.

As expressões simbólicas da Arte brotam da matéria disforme de nossos sonhos e indignações, de nossa relação de espantamento e de perplexidade diante da plasticidade dos fenômenos, das vicissitudes do mundo, dos influxos da vida cotidiana. Co-movidos pelo pathos que arrebata, impulsiona e nos precipita nas venturas do existir, somos compelidos à fruição sensível do vivido/vivente, de modo in-tensivo e desinstalante. $O$ pathos transgressivo da Arte, com seu cunho anárquico e com a verve de seu impulso criador, de sua pulsão criante, nos inspira e nos implica em processos de criação e de invenção de imagens e formas sensíveis que transfiguram os fenômenos humanos, que os recriam e os ressemantizam; que, mediante a polifonia de seus símbolos, os re-velam em suas dimensões e camadas mais vastas e originárias traduzindo as intensidades do anímico.

Essa transfiguração se traduz na composição e na materialização de formas poéticas que apresentam a in-tensidade de nossas sensações e sentires, em suas tonalidades mais diversificadas, nas sagas da tragicomicidade do humano. Formas poéticas que se plasmam mediante a potência de nossa sensibilidade e imaginação criantes no descortinar de suas ressonâncias quânticas. A plasticidade estésica dessas estampas poéticas, tecidas com a fineza de seus relevos e cores, de seus silêncios e sons, de seus recurvamentos e espessuras, proporciona novos sentires e Sentidos, novos modos e perspectivas de relação com a vida, com o mundo, no dinamismo de seus fluxos.

A Arte, ao tocar com intensidade na imanência de nossa sensibilidade, de nossa intuitividade, de nosso imaginário mítico, portanto, nos desvãos da condição humana, em suas instâncias originárias e pregnantes, nos conduz aos confins da demesura, dos estados oblíquos do existir, ao âmago magmático do coração e da alma; nos anima com os feixes do elã vital; infunde o anímico nos desvãos da terceira margem em que podemos fruir os Sentidos humanos primordiais.

Na terceira margem nos incursionamos além dos limites determinados pelas vias retilíneas, pelas lógicas binárias e excludentes, dos limites da 128 Número temático: Desenho e Educação: Cultura Visual e Cidade. A Cor das Letras - UEFS, n. 
primeira e segunda margens, e nos precipitamos nas encruzilhadas dos entre-lugares, nos desvãos do fundo sem fundo, do abismal, nos amálgamas dos entrecruzamentos em que coexistem, in-tensivamente, o limite e o deslimite, o visível e o invisível, o mensurável e o incomensurável. Na terceira margem prevalecem as lógicas da includência, da complementaridade e da interdependência das polaridades interpolares do existir humano.

O advento da sensibilidade, do cuidado com o sensível, da busca da delicadeza, do espírito de fineza e de poeticidade, proporcionados pelas expressões simbólicas da Arte, pode, portanto, propiciar o burilar do estado anímico de nosso ser-sendo, na busca permanente da vivência dos valores humanos, das metamorfoses que nos renovam e vivificam, que podem nos tornar melhores uns com os outros. O elã do estado poético pode operar a alquimia que converte o feio em bonito, o metal pesado em ouro, mediante os processos in-tensivos de transmutação de valores, de sentires e de posturas que nos tornam mais humanos, amorosos e altivos. Este estado nos possibilita compreender e vivenciar os paradoxos e ambiguidades do humano em que nosso existir se constitui, complementarmente, de dor e de prazer, de tristeza e de alegria, de feieza e de boniteza. As expressões simbólicas da Arte podem nos proporcionar estados de "harmonia conflitual" em que aprendemos a dançar melhor com os fluxos tensoriais de suas ambivalências, de suas torsões pregnantes.

Ranz (1999, p. XVIII) ponteia:

El arte... experiencia unitaria en la que cielo y tierra, luz y sombra, dia y noche, fuego y agua, hombre y mujer, materia y espíritu se encuentran piel con piel, frontera con frontera, fundidos en un cosmos de colores, formas, notas, ritmos y silencios...

A Arte se instaura na interligação e no entrecruzamento entre Caos e Cosmos - a Caosmose de Guattari (1992)-, entre Desordem e Ordem, como instâncias que potencializam os processos de criação e de transmutação. Atravessa os hemisférios direito e esquerdo do cérebro ao mobilizar nossas disposições sensíveis e intuitivas conjuntamente com nossas disposições racionais e analíticas. Ela é androgínica ao fomentar a juntura simbiótica e in-tensiva entre os símbolos do masculino (Apolo) e do feminino (Dioniso), como potencialidades energéticas, sinergéticas, que constituem a inteireza de nosso ser-sendo. Simbiose que se traduz na relação de coexistência fecunda e criante entre essas polaridades interpolares. Essa coexistência não incide na redução de uma polaridade na outra, mas em sua interligação movente e vigorosa. É no interfluxo da relação in-tensiva de 
copulação entre as diferenças - na interpolaridade - que podem ser fecundados os processos de engravidação e de partejamento do novo, dos Sentidos anímicos do existir.

Nesse rumo, a Arte entrelaça subjetividade e objetividade na proporção em que amalgama o dentro e o fora, as dimensões mais internas de nosso existir (sentimentos, crenças, valores...) - as intensidades - com as dimensões mais externas (formas, signos/símbolos, racionalidade...) - as extensidades. Cassirer (1994, p. 238) afirma que "Quando estamos absortos na intuição de uma grande obra de arte, não sentimos uma separação entre os mundos subetivo e objetivo". A Arte entrecruza as esferas do consciente e do inconsciente. Desse modo, sua vivência e fruição potencializam o ultrapassamento das dicotomias que separam e mutilam as esferas que nos constituem humanamente na composição do dinamismo de nossa inteireza.

As potencialidades criadoras e transmutantes das miragens da Arte, nas texturas do estado poético, conduzidas pela inteligência sensível e espirituosa, mobilizadas por sentimentos altivos e sublimes, mediante o poder incomensurável de nossa imaginação e sensibilidade criantes, opera com nossas dores, conflitos e angústias como motes, como forças e momentos seminais e germinais. Motes e momentos que podem, como vimos, nos inspirar para os fluxos de transformação, de partejamentos que renovam e alargam.

Assim, os feixes tensoriais dos conflitos, os rasgos das dores do mundo que nos perturbam e até nos fazem chorar, com sua agudeza cortante, podem se configurar como momentos promissores das travessias e se converter em passagens alvissareiras. Passagens que, mediante nossa sensibilidade e imaginação criantes, podem se desdobrar no riso desmesurado da contenteza que resulta do nascimento amanhecente do novo que vivifica.

Mobilizando nossos sentires mais in-tensos e inefáveis, os espectros da Arte nos inspiram e nos levam ao vicejar dos estados de fruição e de alumbramento; nos precipitam no estado poético, nas texturas da poeticidade do ser-sendo, em que a vida se desborda nas intensidades de seus fluxos, de sua tragicomicidade. Destarte, o existir pode se descortinar altaneiro com a pujança in-tensiva dos ciclos interligados de seus outonos, invernos, verões e primaveras. 


\section{ARTE: SINERGIA, RELIGAÇÃO E ECOFRATERNIZAÇÃO}

O verdadeiro objeto da arte é criar agregados sensíveis

(Deleuze).

A arte aparece como uma fada encantadora que redime e cura [...] é essencialmente a afirmação, a bênção e a deificação da existência

(Nietzsche).

A experiência/vivência profunda com as expressões dos símbolos da Arte, ao nos conectar com as dimensões internas e sutis de nosso sersendo, pode nos interligar a todos, na proporção em que cultivamos os tesouros da alma e do coração, os sentimentos sublimes da beleza que ultrapassam os preconceitos e os dogmas que enfeiam e segregam. Desse modo, as intensidades, os estados de rebelião, de fruição e de encantamento que a Arte propicia traduzem abertura de espírito e de coração para que aprendamos a derrubar as muralhas que nos separam de nós mesmos e dos outros. Assim, podemos, in-tensivamente, abraçar a nós mesmos, os outros, e nos abraçar com todos os seres no acolhimento e na celebração das diferenças que nos enriquecem como humanos, que tornam o existir e o co-existir admiráveis.

Na proporção em que os símbolos da Arte tocam nossos sentimentos mais fundos e singelos, estes nos dis-põem e mobilizam para momentos celebrativos em que, despojados e abertos, podemos compartilhar com os outros nossas alegrias e tristezas, nossos sonhos e utopias; em que podemos urdir a teia dos laços afetivos da compaixão, da simpatia e da empatia, da solidariedade, da fraternura. A experiência expansiva que as manifestações da Arte nos propicia pode fazer jorrar a sinergia que nos entrelaça no cultivo dos valores e sentimentos mais preciosos, nos impelindo às buscas da beleza supremada; nos infunde o elã do anímico que faz vicejar a dinâmica in-tensiva da unidade na multiplicidade através da plasticidade de suas formas simbólicas.

As expressões simbólicas da Arte, ao nos mobilizar para esses estados intensos em que se desbordam os sentimentos mais vastos, para os ermos do sentimento do mundo, ao nos dis-por para a relação de simpatia que nos sinergiza, podem possibilitar a dissolução de nós e de couraças que aprisionam e enrijecem; podem nos aproximar com mais intimidade e desnudamento de nós mesmos e dos outros. 0 estado de fluidez e de ludicida- 
de das proezas da Arte, no jogo de seus movimentos sincopados, de seus matizes de gratuidade e de inutileza, co-move e mobiliza o corpo e o espírito nas travessuras de suas folias e celebrações, na abertura graciosa do riso que resvala alegria e contenteza. Assim, podemos vicejar o feixe lampejante dos sentimentos de ternura e de acolhimento, de compaixão e de cordialidade na partilha e na fruição das coisas simples, da grandeza supremal dos enigmas do existir humano e dos outros seres do universo.

As formas dos símbolos expressivos da Arte, em seu sentido originário, despontam a partir das dimensões imensuráveis de nosso imaginário mítico, mitopoético, e, portanto, traduzem arquétipos profundos de nosso inconsciente coletivo. Dessa forma, as imagens, os símbolos da Arte, em suas camadas recurvadas, re-velam sonhos, desejos e crenças coletivas que povoam a humanidade, em seus repertórios mitopoéticos, inspiradores e alumbrantes. Projetam o estandarte de nossas utopias e esperanças no dinamismo de seus ritos de celebração e de re-encantação da vida.

A Arte não explica, nos implica. O explicar tende a separar e fragmentar. O implicar nos cumpliciza, nos en-volve e nos simpatiza/empatiza com os outros, com a vida, com as coisas. Com essa potencialidade de nos dispor para a abertura simpatizante e aproximante, de fomentar os liames que interligam, a Arte pode compelir a atitudes entrelaçantes que podem nos fraternizar, nos ecofraternizar (com todo o universo). Nos conduz a posturas de reconhecimento do brilho de cada estrela humana (de si mesmo e dos outros) na constelação da teia do humano, do ecohumano. Dessa forma, podemos sorver a fruição das centelhas, das energias, dos "agregados sensíveis" que fazem vibrar a radiância do humano, do profana e divinamente humano, através dos elos que nos sinergizam e entrelaçam na afirmação de nossa condição de seres singulares e semelhantes, com a pluralidade de nossas diferenças.

Irradiados com esse elã sensível, podemos converter as formas singulares de nossas diferenças em condições que nos dis-põem a compartilhar a diversidade de sentimentos e de valores, por meio daquilo que nos une - 0 núcleo da condição humana: o pulsar de nossos corações e o vibrar de nossas almas. Pulsar que, se estamos dis-postos para tanto, pode nos fazer arrepiar na in-tensidade do laço terno do abraço caloroso que nos amoriza.

Nessa perspectiva, a Arte se re-vela como emanação de formas alumbradas de celebração da vida que conduzem à sua renovação permanente nos fluxos tensoriais dos movimentos cíclicos de suas estações. Com seu tom iniciático, a Arte, mediante os mais diversos ritos de iniciação (ma132 Número temático: Desenho e Educação: Cultura Visual e Cidade. A Cor das Letras - UEFS, n. 
nifestações e celebrações coletivas), nos inicia nas aprendências e coaprendências de nosso ser-sendo-com, nos horizontes do anímico. Assim, co-movidos pelo seu elã vital, podemos, nas proezas de cada aventura, renascer nas franjas dos arrebóis de cada alvorecer; podemos renascer redivivos.

Ao mobilizar a sensibilidade, ao nos co-mover, a Arte compele o espírito e o coração potencializando ações altaneiras que nos en-volvem e sinergizam, que nos entrelaçam como humanos no dinamismo dos ritos de celebração da vida através da dança, do teatro, da poesia, da música etc. Ritos que, portanto, podem nos impulsionar nos compassos da fraternização, da ecofraternização.

Como expressões vívidas que incidem na celebração da vida, as linguagens simbólicas da Arte proporcionam encontros mestiços, encruzilhadas híbridas, em que a diversidade de valores e de cosmovisões, de crenças e de sentires pode se interpenetrar com in-tensidade, na composição desafiadora da estampa mestiça que pode envidar o flamejar "da compaixão do coração, do humanismo do espírito" (MORIN, 1990, p. 23). Despojados e simpatizados nessa teia do ser-sendo-com-os-outros, do estar a-conte/cendo, na fruição do estado poético que nos anima e nos co-move, que nos implica e nos co-implica, podemos fruir a jorrância dos sentimentos, tão difíceis e desafiadores, quanto preciosos e altaneiros da amorosidade ecofraternizante.

Sabemos que, nas populações que constituem as diversas tradições artístico-culturais, também estão presentes as posturas etnocêntricas que tendem a segregar e excluir. Porém, também sabemos/sentimos que, em muitas das experiências coletivas plasmadas mundo afora, essa potencialidade agregadora e entrelaçante da Arte tem se afirmado e se expandido, mesmo que em suas proporções microfísicas. Essa perspectiva se traduz em desafios intensos.

A abertura e a plasticidade do estésico, do vigor de nosso ser sensível que fomentam e mobilizam a imaginação criante nos processos de criação de imagens poéticas, co-movem o corpo e o espírito, a alma e o coração humanos, na manifestação de sentimentos intensos e finos. A vibração dos acordes desses sentimentos ecoa ressonâncias que podem nos en-volver com intensidade e que podem fazer irradiar, para nós e para os outros, a empatia entrelaçante, através dos fios invisíveis das sinergias que nos coimplicam, que nos conduzem ao espírito de compartilhamento e de solidariedade, de afirmação e de reencantação da vida, do mundo. 
Essas ressonâncias, provocadas pela vivência oceânica com a fruição da Arte, suscitam nossa sensibilidade e consciência compreensiva para a escuta e a percepção de nossa condição de seres coexistentes, complementares e interdependentes, na teia viva e in-tensiva da vida, da cultura, do universo/pluriverso. Dessa forma, as expressões da Arte fomentam o sentimento anímico de nosso co-pertencimento na teia planetária do ecossistema.

De modo geral, com as devidas exceções, as instituições religiosas, os partidos políticos, as diversas instituições sociais etc. tendem a segregar e excluir, desencadeando posturas intolerantes, etnocêntricas e reducionistas, cimentadas em ideologias que se pretendem portadoras de verdades únicas e imutáveis. Dessa forma, os espíritos e os corações se armam e se enrijecem na instauração de relações e de posturas frias e ressentidas que incidem em competição e barbárie.

Os lampejos da expressão do "sentimento do mundo" proporcionados pela Arte, podem nos dis-por para o estar-sendo-com-os-outros, na nervura in-tensiva do mundo vivido/vivente, para os laços que nos aproximam e interligam. Lampejos que, assim, nos abrem e nos impelem para a vivência compartilhada da poeticidade do existir e do co-existir, do dinamismo da dança in-tensva e co-movente do cosmos com seus ritmos e contornos mestiços e transversais.

Em todo o mundo, cada vez se expande um pouco mais a emergência de grupos, ONGs, movimentos diversos que, através dos múltiplos símbolos da Arte, plasmam e envidam projetos, vivências e celebrações que, com a intensidade do pathos criador, do elã da poeticidade da Arte, vão afirmando a vida, os valores humanos, infundindo o estado anímico e ecofraternizante nos compassos fecundos de reencantamento do mundo - ao menos de alguns mundos, em pequenos mundos. Nesse sentido, concebo Arte, não como um mero instrumento ou recurso pedagógico, mas, de acordo com o que vimos anteriormente, como uma forma de conhecimento ontologicamente constituída que, com suas características e sentidos peculiares, pode proporcionar a fruição desses processos de religação e de reencantamento da vida, dos mundos possíveis.

Na proporção em que toca fundo em nossa sensibilidade, em nossos sentires, imaginário e intuição, o cuidado primoroso e sensível para com a plasticidade do estésico, da fruição estética do mundo potencializado através das linguagens de Arte nos conduz também aos territórios da Ética. Assim, os sentimentos do bem, da liberdade, da paz, da dignidade, do altru134 Número temático: Desenho e Educação: Cultura Visual e Cidade. A Cor das Letras - UEFS, n. 
ísmo etc. são compreendidos como constitutivos da magnitude da condição humana. Ética (dignidade) e Estética (boniteza) configuram, portanto, instâncias estruturantes da condição humana, de forma implicada e coexistente, na complexidade de sua inteireza aberta e híbrida.

Nesse horizonte compreensivo, as expressões simbólicas da Arte, em sua condição mais originária e anímica, agregam coexistencialmente a Ética e a Estética, o bem e o belo, a delicadeza e a elegância, o útil e o agradável, o sentimento e o pensamento, no cuidado com essa inteireza dinâmica e intensiva da condição eternamente precária e inacabada do existir humano.

A Arte se plasma como experiência orgânica, penetrante, que atravessa por dentro, pelas entranhas da nervura do vivido, do vivente, e implica no cultivo de nossa subjetividade vital, ao mesmo tempo em que afirma e nos conduz ao dinamismo das relações intersubjetivas. Assim, os símbolos da Arte potencializam interligações e interpenetrações ao nos enredar nas estampas da teia animada que entretece o humano, o interhumano, podendo fazer ecoar as ressonâncias dos versos que versejam o universo, na roda mestiça e pregnante que vislumbra a ecofraternização.

As urdiduras poéticas da Arte, como vimos, trazem graça e encantação, podendo nos tornar mais graciosos e altaneiros. Essas urdiduras nos imergem pelos desvãos do sublime, da sutileza, dos mistérios inefáveis do ser, do universo, da tragicomicidade do humano. Nos dis-põem com mais audácia e terneza para as travessuras das travessias oblíquas que nos atravessam e que atravessamos. Assim, podemos trilhar em nossas sagas com mais denodo e paixão, com mais inventividade e vigor, com mais poeticidade e alumbramento. As urdiduras da Arte nos precipitam com afinco e desprendimento pelas ondulações da tensividade do vivido para que possamos bailar com mais desenvoltura nos volteios de suas curvaturas.

A potência criante da Arte nos renova e nos reinventa cotidianamente. Nos metamorfoseia nos ciclos das estações de nossos verões, invernos, outonos e primaveras. Infunde os sentimentos dos estados de alumbramento que nos co-movem nas itinerrâncias nômades, no desbordar de nossas utopias. Renova o espírito e o coração na movência dos fluxos de nosso ser-sendo-com-os-outros, no advento e na fruição do novo que renova e reencanta.

Como estampas híbridas de arco-íris em flor, os símbolos da Arte constelam os fractais das curvaturas e dos entrecruzamentos do existir, de sua teia policrômica e semovente, de seus silêncios e sons, mediante o arco do abraço intercultural/transcultural. Abraço que, de modo in-tensivo, en- 
trelaça os tons multicores de nossas tradições culturais. Os símbolos mitopoéticos da Arte nos dis-põem para os desafios da aventura poética de estar no mundo com os outros vislumbrando o extraordinário, os desvãos da terceira margem.

\section{Elogio à Arte}

A vida sem o tom da Arte

Fica murcha e desbotada

Tudo se torna pesado e frio

Numa rotina desencantada.

A arte viceja a vida

Floresce mente e coração

Nos faz sorver a beleza

Ao mundo dá encantação.

Arte rima com magia

Na animação do elã vital

Rutila o brio da existência

Floreja o poético, o sacral.

A arte comove a vida

Da lama germina a flor

Borda a desmesura do ser

Enigma, paixão e fulgor.

No esmero da obra prima

A fruição do bem e do belo

A alegoria da metamorfose

Diviniza o humano singelo.

As musas inspiram a música

Nos acordes de uma canção

Que exulta nossos sentimentos

Nos dança de êxtase e paixão.

A poesia põe magia nisso

Alumbra a saga do viver

Palavras de claro enigma

Verso, vertigem e alvorecer.

Os entornos das artes plásticas

136 Número temático: Desenho e Educação: Cultura Visual e Cidade. A Cor das Letras - UEFS, $n$. 
Esculpem o corpo do belo

Pintam as cores da fantasia

Desenham os traços do singelo.

O teatro desnuda a vida

Revela as sendas do ser

$\mathrm{Na}$ dança os deuses bailam

Corpos alados a florescer.

\section{REFERÊNCIAS}

ANDRADE, Carlos Dummond. Sentimento do mundo. Rio de Janeiro: Record, 2000.

ARAÚJO, Miguel Almir L. de. Laços de encruzilhada: ensaios transdisciplinares. Feira de Santana: UEFS, 2002.

ARAÚJO, Miguel Almir Lima de. Os sentidos da sensibilidade: sua fruição no fenômeno do educar. Salvador: EDUFBA, 2008.

CAMPOS, Maria José Rago. Arte e verdade. São Paulo: Loyola, 1992.

CASSIRER, Ernst. Ensaio sobre o homem: introdução a uma filosofia da cultura humana. São Paulo: Martins Fontes, 1997.

DELEUZE, Gilles; GUATARI, Félix. O que é filosofia? Rio de Janeiro: Ed. 34, 1992.

DUARTE JÚNIOR, João F. Fundamentos estéticos da educação. Campinas: Papirus, 1988.

FISCHER, Ernst. A necessidade da arte. Rio de Janeiro: Zahar, 1976.

GUATTARI, Felix. Caosmose: um novo paradigma estético. Rio de Janeiro: Ed. 34, 1992.

JUNG, Carl G. O espírito na arte e na ciência. Petrópolis: Vozes, 1991.

MORIN, Edgar. O método 5: a humanidade da humanidade: a identidade humana. Porto Alegre: Sulina, 2002.

MORIN, Edgar. Amor poesia sabedoria. Rio de Janeiro: Bertrand Brasil, 1998.

MORIN, Edgar. A carta de identidade terrena. Revista Margem Condição planetária. FCS PUC/SP, n. 3, dez. 1994.

NIETZSCHE, Friedrich. Obras incompletas: o nascimento da tragédia no espírito da música; humano, demasiado humano; aurora; a gaia ciência; assim falou Zaratustra. Vol. I Col. Os pensadores. São Paulo: Nova Cultural, 1987a.

NIETZSCHE, Friedrich. Obras incompletas: a filosofia na época trágica dos gregos; para além do bem e do mal; para a genealogia da moral; o anticristo; ecce homo. Vol. II. Col. Os pensadores. São Paulo: Nova Cultural, 1987b.

NOVAES, Adauto. (Org.). Artepensamento. São Paulo: Cia. das Letras, 1994.

NUNES, Benedito. Introdução à filosofia da arte. São Paulo: Ática, 1989.

PAVIANI, Jayme. A racionalidade estética. Porto Alegre: Edipucrs, 1991. 
PESSOA, Fernando. Ficções de interludio. Rio de Janeiro: Nova Fronteira, 1980.

RANZ, Ángeles Garcia. El artista interior: de lo espiritual en el desarrollo artístico. Mexico: Ed. Piensa, 1999. 